\title{
Titanium-interlayer mediated hydroxyapatite coating on polyetheretherketone: a prospective study in patients with single-level cervical degenerative disc disease
}

\author{
Ce Zhu ${ }^{1,2+}$, Miaomiao He ${ }^{3 \dagger}$, Lili Mao ${ }^{4}$, Tao Li ${ }^{1}$, Li Zhang $^{3}$, Limin Liu ${ }^{1 *} \mathbb{0}$, Ganjun Feng ${ }^{1 *}$ and Yueming Song ${ }^{1}$
}

\begin{abstract}
Background: Currently, there are limited reports regarding investigation of the biological properties of polyetheretherketone (PEEK) coated with titanium (Ti) and hydroxyapatite (HA) in human. The objective of this study is to evaluate the in vivo response of the PEEK cages coated with Ti and HA versus uncoated PEEK cages after anterior cervical discectomy and fusion (ACDF) in patients with single-level cervical degenerative disc disease (CDDD).

Methods: Twenty-four patients with PEEK cages coated with Ti and HA (PEEK/Ti/HA group) were matched one-toone with patients with uncoated PEEK cages (PEEK group) based on age, gender, and operative segment. All patients had been followed up for more than 2 years. Radiological assessments included intervertebral height $(\mathrm{IH}), \mathrm{C} 2-7$ angle (C2-7a), segmental alignment (SA), and fusion rate. Clinical parameters included Visual Analogue Scale (VAS) and Japanese Orthopedic Association (JOA) scores.

Results: There was no statistical difference in $\mathrm{SA}, \mathrm{IH}$, and C2-7a between the two groups before and after surgery and all these parameters were restored postoperatively. The fusion rate of PEEK/Ti/HA group was significantly higher than PEEK group at 3-month post-operation (87.5\% vs. 62.5\%). At the last follow-up, the fusion rate of the both groups achieved 100\%. The VAS and JOA scores were comparable between two groups and improved postoperatively.

Conclusions: In patients with single-level ACDF, PEEK cage coated with Ti and HA provided a higher fusion rate than uncoated PEEK cage at 3-month post-operation, while both two cages could achieve solid osseous fusion at the last follow up. Compared with the uncoated PEEK cage, PEEK/Ti/HA cage yielded similar favorable segmental and overall cervical lordosis, IH, and clinical outcomes after the surgery.
\end{abstract}

Keywords: Polyetheretherketone, Titanium, Hydroxyapatite, Cage, Cervical degenerative disc disease

\section{Background}

Anterior cervical discectomy and fusion (ACDF) was first described by Robinson and Smith and popularized by Cloward in the 1950s [1, 2]. It is the most widely

\footnotetext{
*Correspondence: liulimin_spine@163.com; gjfenghx@163.com

${ }^{\dagger} \mathrm{Ce}$ Zhu and Miaomiao He contributed equally to this work

1 Department of Orthopedics Surgery and Orthopedics Research

Institute, West China Hospital, Sichuan University, No. 37 Guoxue Road, Chengdu 610041, Sichuan, China

Full list of author information is available at the end of the article
}

used method for the surgical treatment of cervical degenerative disc disease (CDDD) via its positive fusion rate and patient self-assessment outcomes [3, 4]. The implant for replacement of diseased disc can provide a mechanical support between the two endplates as well as facilitate bone growth between the two vertebral bodies [5]. Autograft is considered to be the gold standard for ACDF because of its favorable biocompatibility and high fusion rates without immunogenicity. However, it needs a second surgical site which increases the

c) The Author(s) 2021. This article is licensed under a Creative Commons Attribution 4.0 International License, which permits use, sharing, adaptation, distribution and reproduction in any medium or format, as long as you give appropriate credit to the original author(s) and the source, provide a link to the Creative Commons licence, and indicate if changes were made. The images or other third party material in this article are included in the article's Creative Commons licence, unless indicated otherwise in a credit line to the material. If material is not included in the article's Creative Commons licence and your intended use is not permitted by statutory regulation or exceeds the permitted use, you will need to obtain permission directly from the copyright holder. To view a copy of this licence, visit http://creativeco mmons.org/licenses/by/4.0/. The Creative Commons Public Domain Dedication waiver (http://creativecommons.org/publicdomain/ zero/1.0/) applies to the data made available in this article, unless otherwise stated in a credit line to the data. 
operative time and blood loss as well as the potential risks for the donor site such as pain, hematomas, seromas, infections and fractures [6].

The complications of autograft aforementioned aroused the exploration of new bone substitutes that could provide sufficient mechanical and biologic properties. The two main materials currently used are titanium (Ti) alloys and polyetheretherketone (PEEK). Titanium alloys are advantageous in their excellent corrosion resistance, high mechanical strength and cytocompatibility, but they are susceptible to stress shielding and may result in subsidence due to its high elastic modulus [5]. In addition, the inherent high radiopacity of titanium alloys may produce metal artifacts in computed tomography (CT) images, which would interfere the assessment of fusion results.

PEEK is a semi-crystalline, synthetic thermoplastic polymer that exhibits excellent fracture toughness, thermal stability and environmental resistance [7]. PEEK has an elastic modulus similar to that of natural bone, which prevent the stress shielding that is often observed in titanium alloys implants. Furthermore, the radiolucency of PEEK helps surgeons observe the bone healing around the implants. Nonetheless, the osteoconductive and osteoinductive properties of the PEEK are relatively unsatisfactory due to its bioinert surfaces. To improve osteoblast responses and bone integration of the PEEK, surface modifications of the PEEK have been proven to be an effective strategy [8].

Hydroxyapatite (HA) is a bioactive calcium phosphate with similarities to the mineral phase of natural bone, which has been used for the coating on PEEK to improve its osseointegration with promising results $[9,10]$. The coating techniques include plasma spraying, spin coating, sandblasting, diazonium chemistry, sputtering and etc. $[8,10,11]$. Among them, plasma spraying is the most widely used commercial coating technique with good reproducibility and high deposition rates [7, 12]. Nevertheless, the adhesion strength of plasma-sprayed HA coatings on PEEK is very poor [10]. Stübinger et al. [13] coated HA films on the PEEK by adding a Ti intermediate layer between the HA film and PEEK using a plasma spraying technique, which demonstrated that the plasmasprayed Ti and HA coatings on PEEK displayed a significant improvement of osseointegration in sheep.

However, to our knowledge, the studies concerning the investigation of the biological properties of PEEK coated with Ti and HA in human are limited. In the present study, a PEEK cage with Ti and HA coatings using a plasma spraying technique was prepared and applied to ACDF for the treatment of patients with single-level CDDD. The objective of this study is to evaluate the in vivo response of the PEEK cages coated with Ti and
HA versus those uncoated PEEK cages after ACDF in patients with single-level CDDD.

\section{Methods \\ Materials and characterizations}

The PEEK cages coated with $\mathrm{Ti}$ and HA respectively by plasma spray were supplied by WEGO Holding Co., Ltd. China (Fig. 1). The top and cross-section view were observed by scanning electron microscope (SEM, JSM7500F, JEOL, Japan), and the corresponding element was analyzed by energy disperse spectroscopy (EDS, JSM-7500F, JEOL, Japan) coupled with SEM. X-ray diffraction (XRD, EMPYREAN, PANalytical B.V., Holland) was carried out to confirm the surface phases on PEEK cage. Compressive testing was performed using universal mechanical testing machine (MTS, model E45, America) with a loading speed of $4 \mathrm{~mm} / \mathrm{min}$.

\section{Clinical assessments}

This was a prospective and non-randomized study. This study was approved by the ethics committee of West China Hospital of Sichuan University and informed consent was obtained from the patients. The patients gave written consent for publication of their clinical details and clinical images. Twenty-four patients with singlelevel CDDD between August 2016 and October 2017 in our department who underwent ACDF with PEEK cages coated with $\mathrm{Ti}$ and $\mathrm{HA}$ (PEEK/Ti/HA group) were included in the study. For comparison, 24 patients who underwent single-level ACDF with uncoated PEEK cages (PEEK group) were matched one-to-one to the patients in the PEEK/Ti/HA group. Matching characteristics included age (within 1 year of one another), gender, and operative segment.

The inclusion criteria were: (1) age $\geq 18$ years, (2) radiculopathy and/or myelopathy from single-level cervical

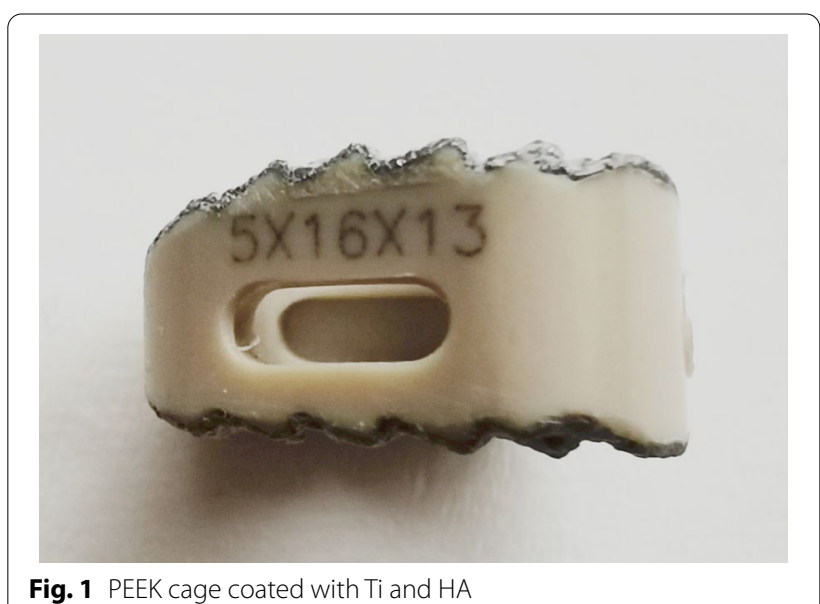


disc herniation, (3) no response to 3 months of nonsurgical management, and (4) no previous spine surgery. Exclusion criteria included previous spine surgery, active infection, and inflammatory spondyloarthropathies.

All operations were performed by the same surgeon under general anesthesia. All procedures were performed through a transverse skin incision on the right side of the neck. Discectomy was performed using a standard anterior cervical approach $[1,14]$. The vertebral body cartilage endplates at the treated level were resected by high-speed burr and curette. The osteophyte located at the posterior edge of the vertebral body, and the ruptured posterior longitudinal ligament were completely removed. The cage with an appropriate size filled with morselized bone from the local decompression was carefully implanted at the decompressed intervertebral space. An ATLANTIS Anterior Cervical Plate System (Medtronic Sofamor Danek USA, Inc. Memphis, TN) was used to achieve immediate stabilization. After surgery, patients were braced in a cervical collar for about 6 weeks.

Frontal and lateral radiographs and three-dimensional CT scans (3d-CT) of the cervical spine were obtained at baseline and the 3-month and final follow-up after surgery (Fig. 2). The following parameters were observed on lateral neutral radiographs (Fig. 3): intervertebral height $(\mathrm{IH})$, the distance from the midpoint of the upper endplate of the upper vertebral body to the midpoint of the lower endplate of the lower vertebral body; C2-7 angle (C2-7a), the Cobb angle between the lower endplate of $\mathrm{C} 2$ and $\mathrm{C} 7$; segmental alignment (SA), the Cobb

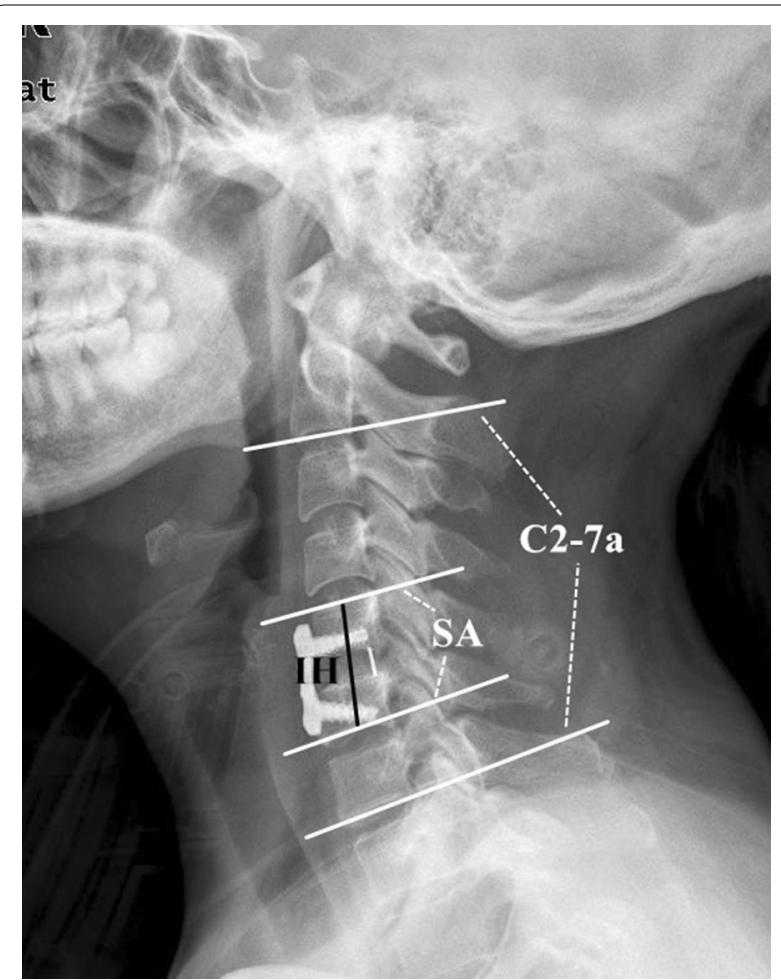

Fig. 3 Representation of radiographic measurements: $\mathbb{H}$ (intervertebral height), the distance from the midpoint of the upper endplate of the upper vertebral body to the midpoint of the lower endplate of the lower vertebral body; C2-7a (C2-7 angle), the Cobb angle between the lower endplate of C2 and C7; SA (segmental alignment), the Cobb angle between the superior endplate of the upper vertebra and the inferior endplate of the lower vertebra of the implanted level

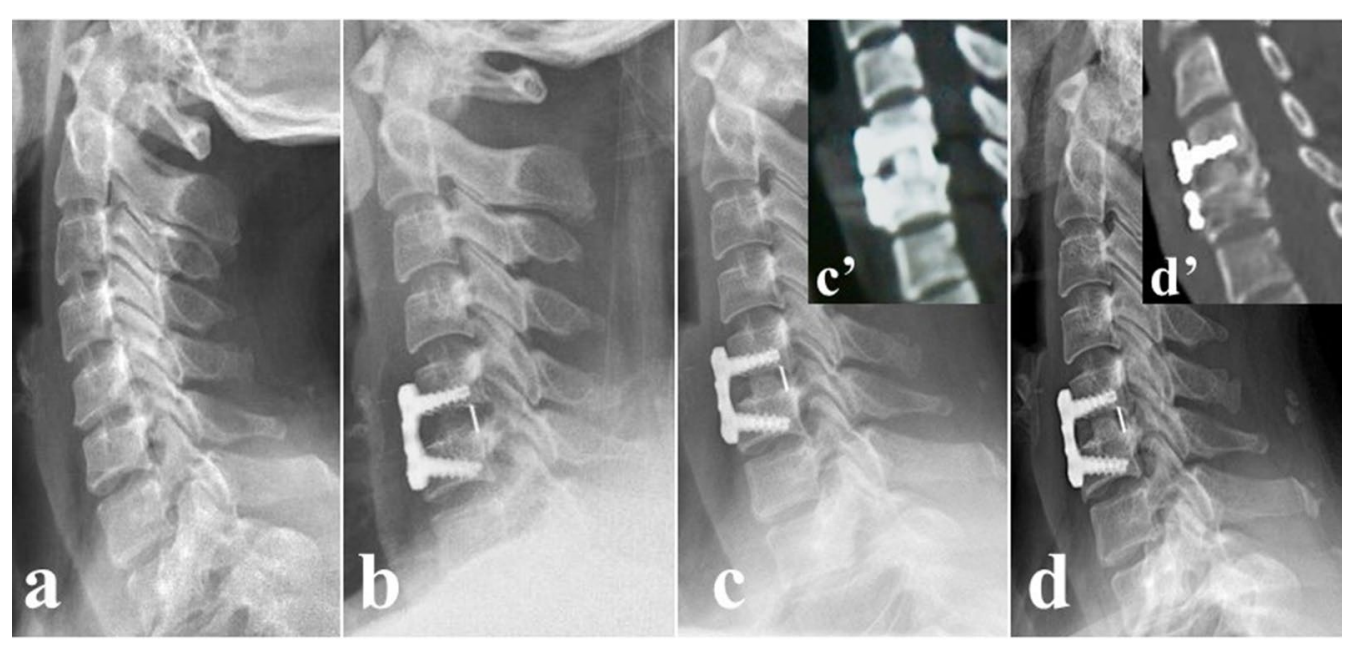

Fig. 2 A 46-year-old woman undergoing anterior cervical discectomy and fusion surgery with a PEEK/Ti/HA cage. a Preoperative plain lateral radiographs image. $\mathbf{b}$ Postoperative lateral radiograph image. $\mathbf{c}$ Lateral radiograph image at 3-month follow-up. $\mathbf{c}^{\prime} \mathrm{CT}$ scans at 3-month follow-up. d Lateral radiograph image at the final follow-up. d' CT scans at the final follow-up. PEEK, polyetheretherketone; Ti, titanium; HA, hydroxyapatite; CT, computerized tomography 
angle between the superior endplate of the upper vertebra and the inferior endplate of the lower vertebra of the implanted level. Negative values indicated kyphosis while positive values indicated lordosis. Subsidence was defined as loss of height of more than $3 \mathrm{~mm}$ [15]. The fusion status was evaluated on $3 \mathrm{~d}-\mathrm{CT}$ by the 5 -grade criteria proposed by Brantigan et al. [16]. The Grades 4 or 5 were defined as fused while Grade 1 or 2 as unfused and Grade 3 was uncertain. All radiological parameters were measured using picture archiving and communication systems (PACS) by 2 attending spinal surgeons who were not involved in the surgery, and the average value of their measurements was used for analysis.

The Japanese Orthopedic Association (JOA) scores and Visual Analogue Scale (VAS) were used for the evaluation of clinical outcomes before surgery, 3 months after surgery and at the final follow-up.

All data were analyzed by using SPSS software (version 22.0; IBM Corp., Armonk, NY, USA). All values are presented as the mean \pm standard deviation. Quantitative data were analyzed by using Student's t-test or the Mann-Whitney U test as appropriate. Categorical data were analyzed by using the $\chi^{2}$ test or Fisher's exact test. Statistical significance was set at $\mathrm{P}<0.05$.

\section{Results}

Figure 4a, b showed the SEM images with different magnifications of the PEEK cage surface. As shown in the images, HA particles with micron sizes stacked on the surface of samples. The SEM image in the cross-section of the cage (Fig. 4c) indicated that Ti layer of approximately $200 \mu \mathrm{m}$ in thickness was located between the PEEK matrix and HA coating, in accordance with the coating treatment sequence. The corresponding EDS line scan (Fig. 4d) in the cross section showed that from the top surface to the matrix, the compositions showed up in the order of $\mathrm{HA}, \mathrm{HA}+\mathrm{Ti}, \mathrm{Ti}$, and PEEK matrix.

The phase structure and crystallinity of the PEEK cage was investigated by XRD and compared with pure Ti (Fig. 5a). The diffraction peaks at $28.9^{\circ}(210), 48.6^{\circ}$ (320), and $48.01^{\circ}(312)$ were detected which indicated the presence of HA (PDF\# 09-0432). The characteristic peak of Ti (PDF\# 44-1294) was also confirmed, indicating the coating was composited by $\mathrm{Ti}$ and $\mathrm{HA}$. The compressive test
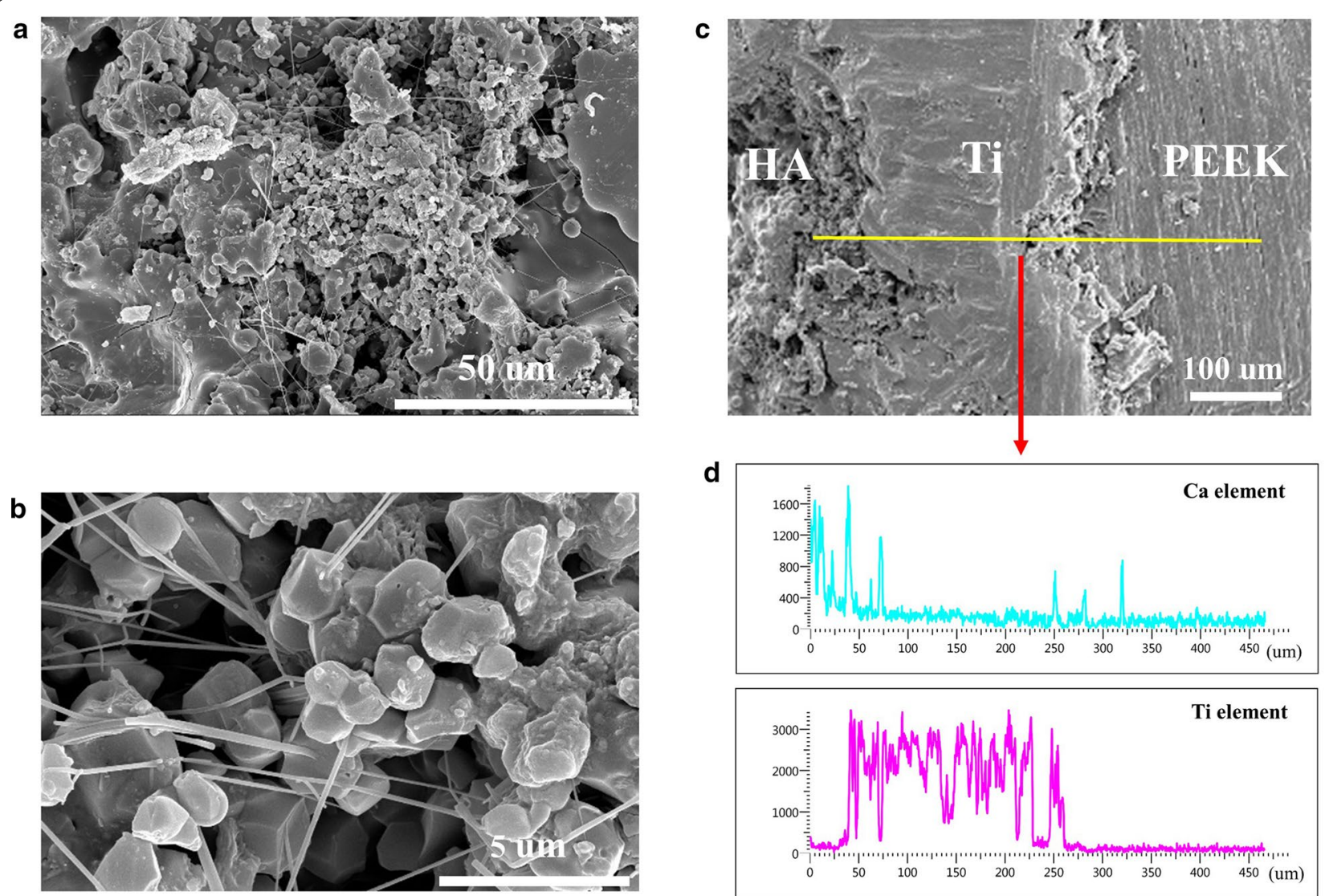

Fig. 4 SEM images of the samples surface with low (a) and high (b) magnification; $\mathbf{c}$ the cross-section SEM images of the samples; $\mathbf{d}$ the corresponding EDS line scanning 

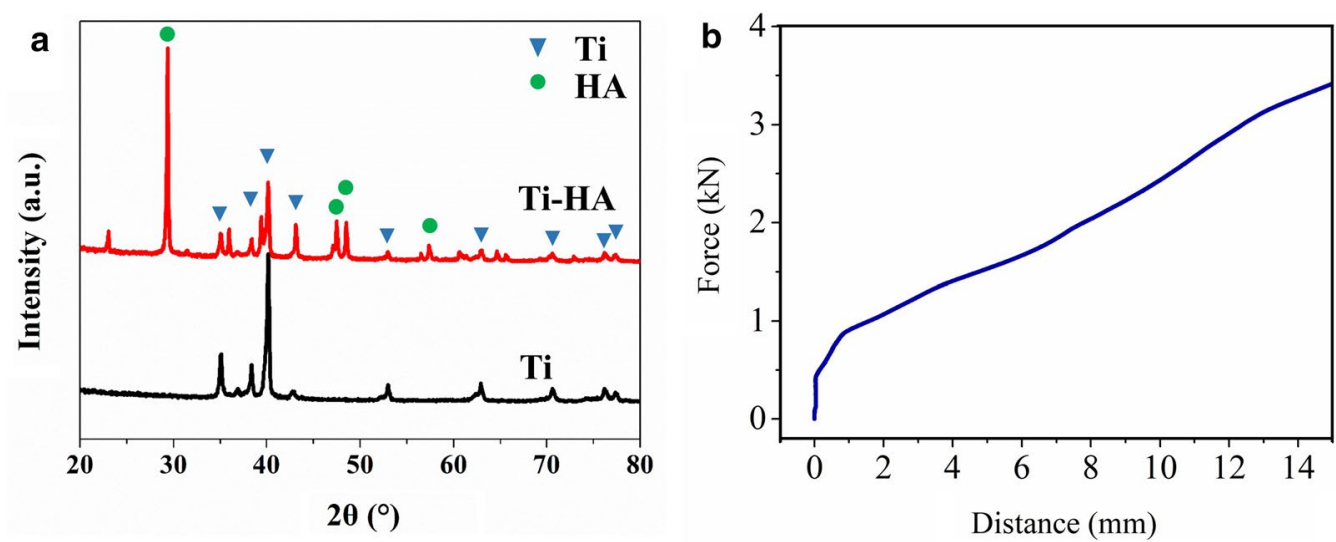

Fig. 5 a XRD of the powder scrapped from coating on the surface of materials respectively; $\mathbf{b}$ the compressive force-distance curve of PEEK cage

Table 1 Patient demographic data

\begin{tabular}{llll}
\hline & PEEK/Ti/HA group & PEEK group & P \\
\hline Age (year) & $49.2 \pm 5.7$ & $49.0 \pm 5.8$ & 0.901 \\
Gender (male/female) & $14 / 10$ & $14 / 10$ & 1.000 \\
Smoker & $7 / 24$ & $5 / 24$ & 0.740 \\
Operative time (min) & $107.2 \pm 15.6$ & $108.5 \pm 15.5$ & 0.782 \\
Blood loss (mL) & $76.8 \pm 18.0$ & $74.2 \pm 19.7$ & 0.633 \\
\hline
\end{tabular}

PEEK polyetheretherketone, Ti titanium, HA hydroxyapatite ${ }^{*} p<0.05$

of PEEK cage (Fig. 5b) showed the cage can bear a load of $0.43 \mathrm{kN}$, which can support the mechanical property required for the spine. The force over $0.43 \mathrm{kN}$ would deform PEEK cage.

The average postoperative follow-up period time ranged from 24 to 41 months (mean $31.5 \pm 6.2$ months). Twenty-two patients $(45.8 \%)$ had radiculopathy (PEEK: $\mathrm{PEEK} / \mathrm{Ti} / \mathrm{HA}=12: 10), 16$ patients $(33.3 \%)$ had myelopathy (PEEK: PEEK/Ti/HA=7:9), and 10 patients $(20.8 \%)$ had both radiculopathy and myelopathy (PEEK: PEEK/Ti/ $\mathrm{HA}=5: 5)$. There was no significant difference between the two groups regarding their diagnoses $(p=0.806)$. The operative segments included C3/4, C4/5, C5/6 and C6/7 $(4,10,22,12$, respectively). There were no significant differences in age, gender, smoker, operative time, and blood loss between the PEEK/Ti/HA group and PEEK group (Table 1).

The radiographic parameters in these two groups were listed in Table 2. There was no statistical difference in $\mathrm{SA}, \mathrm{IH}$, and $\mathrm{C} 2-7 \mathrm{a}$ at baseline, 3-month and at the final follow-up after surgery between the two groups $(\mathrm{P}>0.05)$. The $\mathrm{SA}$ and $\mathrm{C} 2-7 \mathrm{a}$ improved significantly in both groups 3 months after surgery, and the effect remained at the final follow-up. The IH
Table 2 Radiological outcomes of the patients

\begin{tabular}{llll}
\hline & PEEK/Ti/HA group & PEEK group & P \\
\hline SA $\left(^{\circ}\right)$ & & & \\
Pre-op & $2.0 \pm 1.1$ & $1.8 \pm 1.1$ & 0.531 \\
3 m post-op & $6.2 \pm 3.3^{*}$ & $6.0 \pm 3.7^{*}$ & 0.841 \\
Final follow-up & $4.9 \pm 2.2^{*}$ & $4.7 \pm 2.5^{*}$ & 0.806 \\
IH (mm) & & & \\
Pre-op & $34.5 \pm 1.5$ & $34.7 \pm 1.6$ & 0.646 \\
3 m post-op & $36.7 \pm 1.1^{*}$ & $37.1 \pm 1.2^{*}$ & 0.215 \\
Final follow-up & $35.5 \pm 1.1^{*, \#}$ & $36.0 \pm 1.1^{*}, \#$ & 0.135 \\
C2-7a ( ${ }^{\circ}$ ) & & & \\
Pre-op & $12.7 \pm 7.4$ & $13.0 \pm 6.9$ & 0.894 \\
3 m post-op & $18.0 \pm 7.8^{*}$ & $19.3 \pm 6.9^{*}$ & 0.533 \\
Final follow-up & $18.5 \pm 8.3^{*}$ & $18.3 \pm 10.0^{*}$ & 0.960 \\
\hline
\end{tabular}

PEEK polyetheretherketone, $T i$ titanium, $H A$ hydroxyapatite, $S A$ sagittal alignment, $I H$ intervertebral height, $C 2-7 a$ C2-7 angle, Pre-op preoperative, $3 \mathrm{~m}$ Post-op 3-month postoperative

${ }^{*} \mathrm{p}<0.05$ compared with pre-op

\# $\mathrm{p}<0.05$ compared with $3 \mathrm{~m}$ post-op

increased significantly in both groups postoperatively, but decreased at the final follow-up. The cage subsidence rate was the same in both two groups $(1 / 24,4.2 \%)$. The fusion rate of the patients in the PEEK/Ti/HA group was significantly higher than that of patients in the PEEK group at 3 -month post-operation $(87.5 \%$ vs. $62.5 \%, \mathrm{P}<0.05)$. However, the difference of fusion rate between the two groups at 6-month post-operation, 1-year post-operation and the last follow-up were not statistically significant (PEEK: PEEK/Ti/HA $=83.3 \%$ : 95.8\%, 100\%: 100\%, 100\%: 100\%; $\mathrm{P}=0.156,1.000,1.000$; respectively).

No intergroup significant difference was found in terms of the clinical outcomes (Table 3). The JOA score 
Table 3 Clinical outcomes of the patients

\begin{tabular}{llll}
\hline & PEEK/Ti/HA group & PEEK group & P \\
\hline JOA score & & & \\
Pre-op & $10.5 \pm 1.2$ & $10.1 \pm 1.1$ & 0.217 \\
3 m post-op & $15.4 \pm 0.8^{*}$ & $15.0 \pm 0.9^{*}$ & 0.114 \\
Final follow-up & $15.8 \pm 0.9^{*, \#}$ & $15.5 \pm 1.1^{*, \#}$ & 0.407 \\
VAS score & & & \\
Pre-op & $7.9 \pm 1.3$ & $7.7 \pm 1.5$ & 0.772 \\
3 m Post-op & $2.5 \pm 1.0^{*}$ & $2.3 \pm 1.0^{*}$ & 0.690 \\
Final follow-up & $2.4 \pm 1.1^{*}$ & $2.3 \pm 1.1^{*}$ & 0.797 \\
\hline
\end{tabular}

PEEK polyetheretherketone, Ti titanium, HA hydroxyapatite, JOA Japanese Orthopedic Association, VAS visual analogue scale, Pre-op preoperative, $3 \mathrm{~m}$ Post-op 3-month postoperative

* $\mathrm{p}<0.05$ compared with pre-op

\# $\mathrm{p}<0.05$ compared with $3 \mathrm{~m}$ post-op

and VAS score of the patients in both two groups were improved after the surgery.

\section{Discussion}

Previous studies demonstrated the benefits of $\mathrm{Ti}$ and/or HA on PEEK surfaces. Lu et al. [17] found the enhancement of adhesion, proliferation, and osteo-differentiation of rat bone mesenchymal stem cells (BMSCs) by introducing titanium ions into carbon-fiber-reinforced PEEK (CFR-PEEK) surface via plasma immersion ion implantation. Walsh et al. [18] reported that the titanium coating dramatically improved the shear strength at the bone-implant interface at 4 weeks and continued to improve with time compared with PEEK. Lee et al. [19] observed higher alkaline phosphatase (ALP) activity, calcium production, and bone sialoprotein (BSP) production of human bone marrow mesenchymal stem cells on the HA-coated PEEK implants than the bare PEEK group in vitro test. They also demonstrated the better biocompatibility and osseointegration of the HA-coated PEEK in vivo minipig model. Stübinger et al. [13] prepared a double-coated CFR-PEEK which made of a first Ti bond layer and a second hydroxyapatite top layer by air plasma spray. Compared to the uncoated PEEK/CFR-PEEK, $\mathrm{Ti}$ coating and HA coating, the double Ti-HA coating achieved the most favorable biomechanical and biological results in a sheep pelvic model.

So far, to the best of our knowledge, there is a limited published data related to osseointegration and biocompatibility of PEEK coated with titanium and HA in human. In this study, we successfully coated PEEK surfaces with rough titanium and hydroxyapatite layers together. And we sought to evaluate the clinical and radiographic outcomes of ACDF using PEEK cages coated with titanium and HA compared to a matched uncoated PEEK cages cohort with a minimal follow-up time of 2 years.

It is generally believed that fusion rate is a critical prognostic factor in ACDF. In the present study, patients in the PEEK/Ti/HA group achieved higher fusion rate than patients in the PEEK group (87.5\% vs. $62.5 \%, \mathrm{P}<0.05) 3$ months postoperatively. Meanwhile, solid osseous fusion was found in all the patients of the both two groups since 1-year post-operation (100\% fusion rate). These results indicated an excellent fusion capability of the PEEK cages coated with Ti and HA. The reasons are both of biological and physical nature of the Ti and HA layers: first of all, the biocompatibility and osteoconductivity of $\mathrm{Ti}$ and $\mathrm{HA}$ is higher than that of PEEK, which have been proved by previous studies $[13,17-20]$. In addition, the rough coating surface provides high initial fixation of the intervertebral space by increasing frictional forces and limiting micromotion $[13,21]$.

Cage subsidence is a common complication of ACDF which relates to kyphotic deformity, instrument failure and postoperative neurologic deterioration [22]. In our study, the cage subsidence rate was the same in both two groups $(1 / 24,4.2 \%)$. The $\mathrm{IH}$ in the PEEK/Ti/ HA group increased from $34.5 \mathrm{~mm}$ preoperatively to $36.7 \mathrm{~mm}$ postoperatively, but decreased to $35.5 \mathrm{~mm}$ at final follow-up, while the $\mathrm{IH}$ in the PEEK group increased from $34.7 \mathrm{~mm}$ preoperatively to $37.1 \mathrm{~mm}$ post-operatively, but decreased to $36.0 \mathrm{~mm}$ at the last follow-up (Table 2). The average loss of height of the fusion segment the PEEK/Ti/HA group and PEEK group was $1.2 \mathrm{~mm}$ and $1.1 \mathrm{~mm}$, respectively $(\mathrm{P}>0.05)$. Fortunately, both of the two patients with cage subsidence did not suffer any associated clinical symptoms and the intervertebral fusion of them was not interfered.

The restoration of physiological lordosis of the cervical spine is crucial to obtaining better dorsal shifting of the decompressed spinal cord and better postoperative clinical outcomes in ACDF [23, 24]. In this study, the segmental and overall cervical lordosis of all the patients were restored postoperatively and maintained well at the final follow-up (Table 2). These results were comparable with the previous studies $[24,25]$. As for the clinical outcomes, the JOA and VAS scores were significantly improved after surgery in both the PEEK/Ti/HA and PEEK groups, and there was no significant difference between the two groups.

Our study had several limitations. First, the sample size was small and the follow-up time was short. Second, we did not enroll the patients with multi-level CDDD. So, future studies with larger numbers of patients with multilevel CDDD and longer follow-up period are needed. 


\section{Conclusions}

A PEEK cage with $\mathrm{Ti}$ and HA was successfully fabricated via a plasma spraying technique. In patients with single-level ACDF, PEEK cage coated with Ti and HA provided a higher fusion rate than uncoated PEEK cage at 3-month post-operation, while both of the two cages could achieve solid osseous fusion at the last follow up (100\% fusion rate). Compared with the uncoated PEEK cage, PEEK/Ti/HA cage yielded similar favorable segmental and overall cervical lordosis, $\mathrm{IH}$, and clinical outcomes after the surgery.

\begin{abstract}
Abbreviations
ACDF: Anterior cervical discectomy and fusion; CDDD: Cervical degenerative disc disease; Ti: Titanium; PEEK: Polyetheretherketone; CT: Computed tomography; HA: Hydroxyapatite; SEM: Scanning electron microscope; EDS: Energy disperse spectroscopy; XRD: X-ray diffraction; MTS: Mechanical testing machine; IH: Intervertebral height; C2-7a: C2-7 angle; SA: Segmental alignment; PACS: Picture archiving and communication systems; JOA: Japanese Orthopedic Association; VAS: Visual Analogue Scale; BMSCs: Bone mesenchymal stem cells; ALP: Alkaline phosphatase; BSP: Bone sialoprotein.
\end{abstract}

\section{Acknowledgments}

We are grateful to Yi Zhu from McMaster University for his kind help in editing the language in this paper.

\section{Authors' contributions}

$\mathrm{CZ}$ and $\mathrm{MH}$ conceptualized and designed the study, drafted the initial manuscript. LM, TL and LZ carried out the initial analyses, reviewed and revised the manuscript. LL, GF, and YS coordinated and supervised data collection, critically reviewed and revised the manuscript for important intellectual content. All authors agree to be accountable for all aspects of the work. All authors read and approved the final manuscript.

\section{Funding}

This work was supported by the Key Research and Development Project of Science \& Technology Department of Sichuan Province [grant numbers: 2017SZ0046 \& 2017SZDZX0021]. The organization had no involvements in the study design, collection, analysis, or interpretation of data, in the writing of the manuscript, or in the decision to submit the manuscript for publication.

\section{Availability of data and materials}

Data will be available upon request to the corresponding author.

\section{Ethics approval and consent to participate}

This study was approved by the ethics committee of West China Hospital of Sichuan University and informed consent was obtained from the patients.

\section{Consent for publication}

The patients gave written consent for publication of their clinical details and clinical images. A copy of the written consent is available for review by the editor of this journal.

\section{Competing interests}

The authors declare that they have no competing interests.

\footnotetext{
Author details

${ }^{1}$ Department of Orthopedics Surgery and Orthopedics Research Institute, West China Hospital, Sichuan University, No. 37 Guoxue Road, Chengdu 610041, Sichuan, China. ${ }^{2}$ Department of Spine Surgery, The Affiliated Hospital of Southwest Medical University, Luzhou, China. ${ }^{3}$ Analytical \& Testing Center, Sichuan University, Chengdu, China. ${ }^{4}$ Department of Ultrasound, Hospital of Traditional Chinese Medicine Affiliated to Southwest Medical University, Luzhou, China.
}

Received: 17 November 2020 Accepted: 22 December 2020

Published online: 06 January 2021

\section{References}

1. Smith GW, Robinson RA. The treatment of certain cervical-spine disorders by anterior removal of the intervertebral disc and interbody fusion. J Bone Joint Surg Am Vol. 1958;40-a(3):607-24.

2. Cloward RB. The anterior approach for removal of ruptured cervical disks. J Neurosurg. 1958;15(6):602-17.

3. Cauthen JC, Kinard RE, Vogler JB, et al. Outcome analysis of noninstrumented anterior cervical discectomy and interbody fusion in 348 patients. Spine. 1998;23(2):188-92.

4. Buttermann GR. Anterior cervical discectomy and fusion outcomes over 10 years: a prospective study. Spine. 2018;43(3):207-14.

5. Park PJ, Lehman RA. Optimizing the spinal interbody implant: current advances in material modification and surface treatment technologies. Curr Rev Musculoskelet Med. 2020;13:688-95.

6. Menon N, Turcotte J, Patton C. Structural allograft versus synthetic interbody cage for anterior cervical discectomy and fusion: a comparison of 1-year outcomes from a national database. Glob Spine J. 2020. https:// doi.org/10.1177/2192568220942217.

7. Buck E, Li H, Cerruti M. Surface modification strategies to improve the osseointegration of poly(etheretherketone) and its composites. Macromol Biosci. 2020;20(2):e1900271.

8. Ozeki K, Masuzawa T, Aoki H. Fabrication of hydroxyapatite thin films on polyetheretherketone substrates using a sputtering technique. Mater Sci Eng C Mater Biol Appl. 2017;72:576-82.

9. Barkarmo S, Andersson M, Currie F, et al. Enhanced bone healing around nanohydroxyapatite-coated polyetheretherketone implants: an experimental study in rabbit bone. J Biomater Appl. 2014;29(5):737-47.

10. Mahjoubi H, Buck E, Manimunda P, et al. Surface phosphonation enhances hydroxyapatite coating adhesion on polyetheretherketone and its osseointegration potential. Acta Biomater. 2017:47:149-58.

11. Rahmitasari F, Ishida Y, Kurahashi K, Matsuda T, Watanabe M, Ichikawa T. PEEK with reinforced materials and modifications for dental implant applications. Dent J. 2017;5(4):35.

12. Kurtz SM, Devine JN. PEEK biomaterials in trauma, orthopedic, and spinal implants. Biomaterials. 2007;28(32):4845-69.

13. Stübinger S, Drechsler A, Bürki A, Klein K, Kronen P, von Rechenberg B. Titanium and hydroxyapatite coating of polyetheretherketone and carbon fiber-reinforced polyetheretherketone: a pilot study in sheep. J Biomed Mater Res B Appl Biomater. 2016;104(6):1182-91.

14. Hu B, Yang $X$, Hu Y, et al. The n-HA/PA66 cage versus the PEEK cage in anterior cervical fusion with single-level discectomy during 7 years of follow-up. World Neurosurg. 2019;123:e678-84.

15. Zhu C, Yang X, Wang L, et al. Comparison of dynamic cervical implant versus anterior cervical discectomy and fusion for the treatment of single-level cervical degenerative disc disease: a five-year follow-up. Clin Neurol Neurosurg. 2018;164:103-7.

16. Brantigan JW, Steffee AD. A carbon fiber implant to aid interbody lumbar fusion. Two-year clinical results in the first 26 patients. Spine. 1993;18(14):2106-7.

17. Lu T, Liu X, Qian S, et al. Multilevel surface engineering of nanostructured TiO2 on carbon-fiber-reinforced polyetheretherketone. Biomaterials. 2014;35(22):5731-40.

18. Walsh WR, Bertollo N, Christou C, Schaffner D, Mobbs RJ. Plasma-sprayed titanium coating to polyetheretherketone improves the bone-implant interface. Spine J. 2015;15(5):1041-9.

19. Lee JH, Jang HL, Lee KM, Baek HR, Jin K, Noh JH. Cold-spray coating of hydroxyapatite on a three-dimensional polyetheretherketone implant and its biocompatibility evaluated by in vitro and in vivo minipig model. J Biomed Mater Res B Appl Biomater. 2017;105(3):647-57.

20. Johansson P, Jimbo R, Naito Y, Kjellin P, Currie F, Wennerberg A. Polyether ether ketone implants achieve increased bone fusion when coated with nano-sized hydroxyapatite: a histomorphometric study in rabbit bone. Int J Nanomed. 2016;11:1435-42.

21. Rao PJ, Pelletier MH, Walsh WR, Mobbs RJ. Spine interbody implants: material selection and modification, functionalization and bioactivation of surfaces to improve osseointegration. Orthop Surg. 2014;6(2):81-9. 
22. Yang X, Liu L, Song Y, Kong Q, Zeng J, Tu C. Outcome of single level anterior cervical discectomy and fusion using nano-hydroxyapatite/polyamide-66 cage. Indian J Orthop. 2014;48(2):152-7.

23. Okuyama K, Miyakoshi N, Sasaki H, Kido T, Shimada Y. ACDF with a PEEK cage clinically provides a good outcome with minor donor site morbidity despite unsatisfactory radiological findings-A prospective cohort study of a PEEK cage in stand-alone usage. Spine Surg Related Res. 2017;1(3):129-34.

24. Yang S, Yu Y, Liu X, et al. Clinical and radiological results comparison of allograft and polyetheretherketone cage for one to two-level anterior cervical discectomy and fusion: a CONSORT-compliant article. Medicine. 2019;98(45):e17935.

25. Gillis CC, Kaszuba MC, Traynelis VC. Cervical radiographic parameters in 1 - and 2-level anterior cervical discectomy and fusion. J Neurosurg Spine. 2016;25(4):421-9.

\section{Publisher's Note}

Springer Nature remains neutral with regard to jurisdictional claims in published maps and institutional affiliations.
Ready to submit your research? Choose BMC and benefit from:

- fast, convenient online submission

- thorough peer review by experienced researchers in your field

- rapid publication on acceptance

- support for research data, including large and complex data types

- gold Open Access which fosters wider collaboration and increased citations

- maximum visibility for your research: over $100 \mathrm{M}$ website views per year

At BMC, research is always in progress.

Learn more biomedcentral.com/submissions 